\title{
Similar but different: distinct roles for KRAS and BRAF oncogenes in colorectal cancer development and therapy resistance
}

\author{
Markus Morkel ${ }^{1}$, Pamela Riemer ${ }^{1,2}$, Hendrik Bläker ${ }^{2,3}$, Christine Sers ${ }^{1,2}$ \\ ${ }^{1}$ Charité Universitätsmedizin Berlin, Institute of Pathology, Laboratory of Molecular Tumor Pathology and Systems Biology, \\ Berlin 10117, Germany \\ ${ }^{2}$ DKTK, German Consortium for Translational Cancer Research, Partner Site Berlin and DKFZ, German Cancer Research \\ Center, D-63170 Heidelberg, Germany \\ ${ }^{3}$ Charité Universitätsmedizin Berlin, Institute of Pathology, Berlin 10117, Germany \\ Corresponding to: \\ Christine Sers, e-mail: christine.sers@charite.de \\ Keywords: KRAS, BRAF, colorectal cancer, signaling, therapy \\ Received: May 07, $2015 \quad$ Accepted: July 17, 2015 \\ Published: July 30, 2015
}

\section{ABSTRACT}

Colorectal cancer (CRC) is characterized by recurrent mutations deregulating key cell signaling cascades and providing the cancer cells with novel functional traits. Among the most frequent mutations in CRC are gain-of-function missense mutations in KRAS and BRAF. Oncogenic activation of KRAS and BRAF is mutually exclusive and occurs in approximately $40 \%$ and $10 \%$ of all CRCs, respectively. Here we summarize genetic alterations currently described in the literature and databases, indicating overlapping but also specific co-occurrences with either mutated BRAF or KRAS. We describe common and potentially specific biological functions of KRAS and BRAF oncoproteins in the intestinal epithelial cells and during initiation and progression of CRC. We discuss signal transduction networks, highlighting individual functions of oncogenic KRAS and BRAF in terms of feedback loops and their impact on treatment outcome. Finally, we give an update on current strategies of targeted therapeutic intervention in oncogenic RAS-RAF signaling networks for the treatment of metastatic CRC and outline future directions.

\section{INTRODUCTION}

KRAS and BRAF as main players in the MAPK network

Cancer cells rely on signaling networks that are self-sufficient in providing growth signals and are refractory to growth inhibitory or apoptosis signals. This is due to multiple activating mutations in protooncogenes and functional loss of tumor suppressor genes [1]. KRAS and BRAF are major oncogenic drivers of colorectal cancer (CRC). They play further important roles in other cancer entities. Roles of KRAS and BRAF in other cancers are not discussed here, but have recently been reviewed elsewhere [2]. KRAS, a small GTPase, acts as a central relay for signals originating at receptor tyrosine kinases such as the EGFR family in the intestinal epithelium and in many other tissues [3].
Receptor tyrosine kinases stimulate KRAS activity via guanine nucleotide exchange factors, which activate KRAS by favoring GTP binding. The negative control is exerted through GTPase-activating proteins, which promote hydrolysis of GTP and thus KRAS inactivation. BRAF is a serine-threonine kinase that can be activated by KRAS and represents the top level element of the RAF-MEK-ERK (MAPK) kinase cascade [4]. MAPK signals regulate proliferation, differentiation, cell motility and further aspects of cellular activity via phosphorylation of many ERK substrates, such as cytoskeletal components and transcription factors. KRAS can also activate other signaling pathways in addition to the MAPK cascade. One of these is the PIK3CA-AKT-mTOR axis, which regulates protein translation and cell survival [5]. Together, the MAPK cascade and intersecting signaling pathways form a highly connected oncogenic network in CRC. 


\section{Mutational patterns of $K R A S, B R A F$ and other MAPK network genes in CRC}

Approximately $40 \%$ of CRCs display activating missense mutations in KRAS [6-8] (the COSMIC database reports $36 \%$ [9], while TCGA reports $42 \%$ of KRAS mutations [10, 11]; Fig. 1). These affect hotspots in codons 12 and 13 (80\% of all KRAS mutations, of these are $\mathrm{G} 12 \mathrm{D}>\mathrm{G} 12 \mathrm{~V}>\mathrm{G} 13 \mathrm{D}>\mathrm{G} 12 \mathrm{C}>\mathrm{G} 12 \mathrm{~A}$ ), codon 61 (4\% of all KRAS mutations, of these are Q61H $>$ Q61L > Q61R) and 146 (1-2\% of all KRAS mutations, mostly A146T and A146V). Furthermore, additional mutations in KRAS at various positions (e.g. 68,117$)$ are cataloged in the databases, yet their functional impact on KRAS protein function is largely unknown.

Structural analyses have presented a rationale for how the most frequent mutations activate KRAS: the glycine residues at positions 12 and 13 are important sites for interaction of KRAS with GAPs, while the glutamine at position 61 is a crucial site for the hydrolysis of GTP [12-14]. Therefore, mutations at either site lock KRAS in an active GTP-bound conformation constitutively presenting a docking surface for RAF kinases, including BRAF and CRAF (RAF1). Differences in clinical outcome have been identified in patients that harbor different KRAS mutations in the codons 12 and 13 [15, 16], although the data are discussed controversially and the mechanistic basis for these findings remains unknown. In addition to mutations, amplification of mutated $K R A S$ and loss of heterozygosity resulting in elimination of the wildtype KRAS allele have been reported [11]. Since non-mutated RAS can limit the effects of oncogenic RAS, allelic imbalances favoring mutated $K R A S$ could further supplement oncogenic KRAS signals [17].

$B R A F$ mutations are less frequent in CRC [18] (COSMIC and TCGA report $11 \%$ and $10 \%$ of CRCs with activating mutations in $B R A F$; Fig. 1) [9-11]. $B R A F$ mutations in CRC are mostly V600E amino acid substitutions, although various other mutations at codon 600 or neighboring positions within the kinase domain are documented, too. Structural studies of RAF proteins have identified the valine at position 600 as a crucial site within the conserved kinase domain, which is required for BRAF to maintain an inactive conformation in the absence of KRAS-BRAF interaction [19]. Mechanistically, mutations at this site likely render mutated BRAF independent from dimerization with BRAF or RAF1, which is normally a prerequisite for activation. Consequently, the V600E

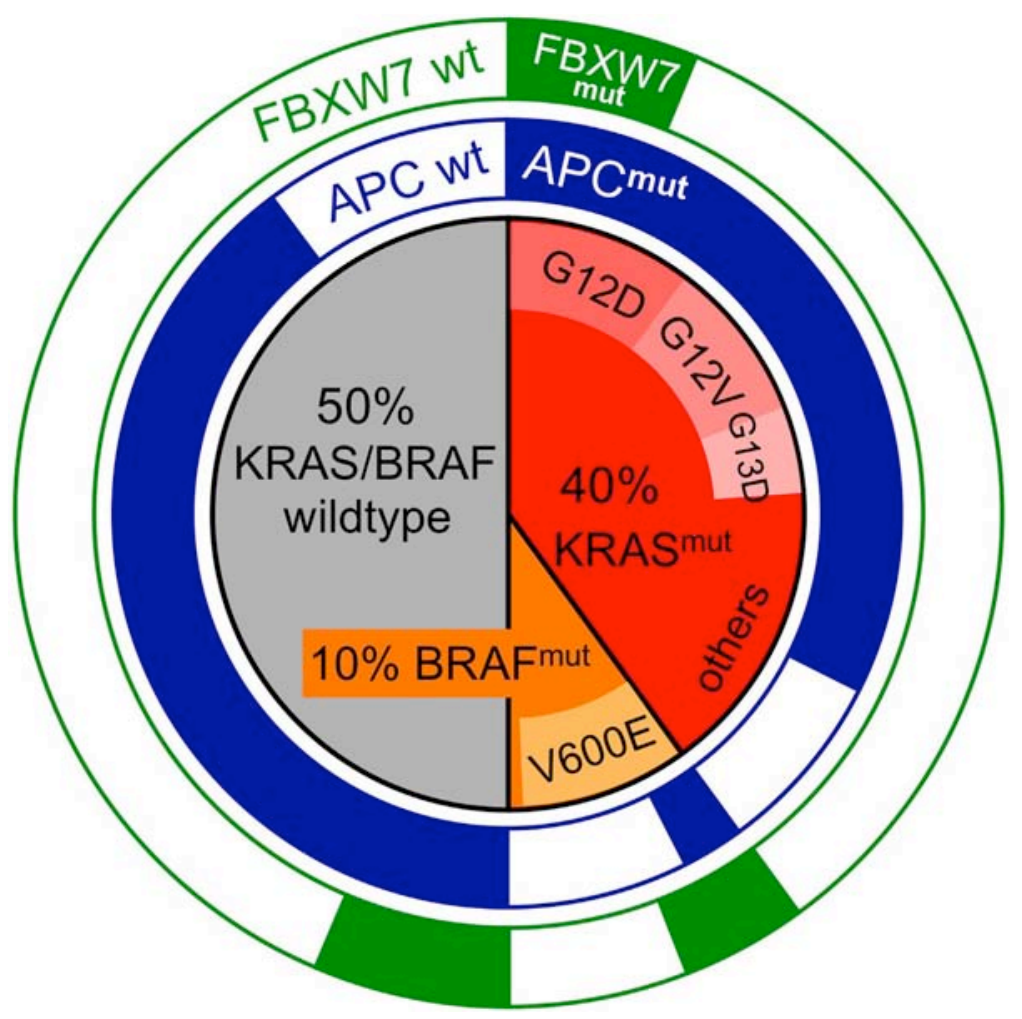

Figure 1: Mutational spectra of $K R A S, B R A F$ and the Wnt effector genes $A P C$ and $F B X W 7$ in $C R C$. Inner circle: fractions of KRAS-mutant (red) and BRAF-mutant (orange) and KRAS/BRAF-wildtype (grey) CRC. The most common mutations are given within the sections. Outer rings: relative proportions of APC-mutant (blue) or FBXW7-mutant (green) CRC found in KRAS-mutant, BRAFmutant and KRAS/BRAF-wt CRC. APC mutations are significantly underrepresented in BRAF-mut CRC, while FBXW7 mutations are overrepresented. Mutational frequencies were derived from the TCGA and COSMIC databases. 
mutation is strongly activating, resulting in constitutive MEK binding, phosphorylation and therefore BRAF signal transduction. $B R A F$ amplification and $B R A F$ loss of heterozygosity have infrequently been detected in CRC [11]. The significance of these $B R A F$ genomic imbalances is unclear, however $B R A F$ copy number gains have been implicated in drug resistance of CRC $[20,21]$.

$K R A S$ and $B R A F$ mutations occur in a mutually exclusive manner in CRC [22] [9-11]. This may suggest that the mutations are functionally redundant during CRC development, i.e. no further selective advantage is provided for a cell by the second mutation when the first is already present. Another explanation for the mutual exclusivity is that mutations in KRAS and BRAF may be functionally incompatible; $B R A F$ mutations would thus have unfavorable effects in KRAS-mutant CRC and vice versa, consequently leading to elimination of cells that have acquired both mutations sequentially. As a further explanation, $K R A S$ or $B R A F$ mutations could provide specific selective advantages that co-depend on the presence of other mutations. In support of this latter scenario, $A P C$ and $K R A S$ mutations frequently co-occur, while APC and BRAF mutations show a significant trend towards mutual exclusivity $[10,11]$. In contrast, mutations in the ubiquitin ligase $F B X W 7$ often co-occur with $B R A F$ mutations, but are less frequent in $K R A S$-mutant or $K R A S /$ $B R A F$-wildtype CRC (Fig. 1). This suggests that $K R A S$, but not $B R A F$ mutations provide a selective advantage specifically in $A P C$-mutant CRC precursor cells, whereas $F B X W 7$ mutations provide the greatest advantage for CRC cells harboring activated BRAF.

While mutations in KRAS and BRAF are the most frequent alterations in the MAPK cascade in $C R C$, further mutations involving other genes have been found. The $K R A S$ homologue NRAS (but not the third RAS family member $H R A S$ ) harbors mutations in $2-4 \%$ of all CRCs, clustering at the amino acid residues Q61 and G12 $[9,11,23]$. It has been argued that the distinct mutational patterns within the RAS family are due to non-redundant regulatory mechanisms and individual cellular functions of KRAS, NRAS and HRAS [24, 25]. ARAF and RAF1 do not show mutations in CRC. A probable explanation for the prevalence of $B R A F$ mutations within the RAF gene family is the presence of a BRAF-specific domain that allows binding of additional interaction partners for RAS interaction [26, 27]. Alternatively, it may be due to the unique mode of activation of BRAF, which is primed for MEK phosphorylation [19, 28, 29]. Indeed, BRAF is a more potent signal transducer from RAS to the MEKERK kinases compared to ARAF or RAF1 [30, 31]. In addition to RAS and RAF family members also NF1, coding for the RAS-regulatory GTPase-activating protein Neurofibromin 1, has been found mutated in some (approx. 4\%) CRCs [32]. Recently, it has been shown that inactivation of $N F 1$ can synergize with oncogenic KRAS and also potentially with non-canonical KRAS mutations [33]. Furthermore, another RAS-GAP encoding gene, $D A B 2 I P$, displays mutations in approximately $8 \%$ of all CRCs, as reported by TCGA. While the nature and consequences of these non-synonymous SNPs is currently unknown, the observations point towards more prominent roles of RAS-associated regulatory processes than previously anticipated. A potential tumor-suppressive role of DAB2IP has recently been highlighted in a prostate cancer model, where $D A B 2 I P$ gene loss activated both RAS and NFאB [34]. In addition, high DNA methylation frequencies of the $D A B 2 I P$ gene have been found in multiple human cancers [35]. Mutations with functional impact on MAPK signal transduction in genes encoding the more downstream MEK and ERK kinases have not been reported in CRC. However, approximately $6 \%$ of CRCs harbor alterations within the MAP $2 K 4$ gene, also called JNKK, a serine threonine kinase within the stressactivated MAPK pathway [10]. Together, alterations in KRAS, NRAS, BRAF, NF1, DAB2IP and MAP2K4 comprise $64 \%$ of the CRC tumors presented by the TCGA dataset. Only BRAF and KRAS mutations appear significantly mutually exclusive, the other mutations can occur within the same samples.

\section{$K R A S$ and $B R A F$ mutations occur in distinct sequences and patterns during CRC development}

Activation of the EGFR-RAS-RAF and the WntAPC- $\beta$-Catenin signaling axes represent key steps in initiation and early progression of CRC $[36,37]$. Indeed, EGFR signals, together with Wnt and Notch signals, form part of a larger signaling network controlling the maintenance of stem cells and the proliferative compartment of the normal intestinal epithelium [38-41]. Pathway-activating mutations represent essential steps during the early phases of CRC development, because they favor stem cell and proliferative characteristics independently of ligands provided by the microenvironment [42-44].

The EGFR-RAS-RAF and the Wnt-APC- $\beta$ Catenin signaling cascades can be activated by different mutations and in different order (Fig. 2). There is ample evidence that different mutational sequences can give rise to different forms of precancerous (adenomatous) lesions. A majority (approx. 70-80\%) of CRCs develop via conventional adenomatous polyps that are initiated by mutations activating the $\mathrm{Wnt} / \beta$-catenin pathway, commonly in $A P C[9,11,45]$. Analyses of different stages of human neoplasia and analyses of differentlysized adenomas revealed that KRAS mutations are rare $(10 \%)$ in small and early adenomas but frequent $(50 \%)$ in larger and more advanced adenomas $[8,46]$. These data imply that $K R A S$ mutations often occur after the initiating $A P C$ mutation in CRC developing from adenomatous polyps. Indeed, mouse tumor models have shown that 
oncogenic KRAS synergizes with loss of APC in intestinal tumor progression: while APC inactivation results in the formation of benign adenoma only, activation of oncogenic KRAS in combination with APC inactivation results in the growth of invasive adenocarcinomas [47, 48]. One mechanism contributing to synergistic effects of the mutations is the convergence of KRAS-RAF1 and APC activities to promote nuclear localization of $\beta$-Catenin and subsequent activation of intestinal cell proliferation [49]. The sequence of events with $A P C / W n t$ being the initiating mutation and $K R A S$ a tumor promoting mutation is probably unique to $A P C$ and $K R A S$. To the best of our knowledge, it has not been demonstrated that $B R A F$ mutations can follow $A P C$ mutations during the development of conventional adenoma, suggesting that BRAF does not perform strictly equivalent functions as KRAS in the intestinal epithelium to promote transformation and cancer progression.

A minor proportion (approx. 20-30\%) of CRCs develop via serrated precursors, such as sessile serrated adenoma or hyperplastic polyps [50-52]. There are multiple lines of evidence that serrated adenomas are initiated via activating mutations in the EGFR-RASRAF signaling axis without prior APC inactivation. A study concentrating on aberrant crypt foci, representing the earliest precursors of CRC, found 10 out of $16(63 \%)$ serrated foci to display $B R A F$ mutations, but only 1 of 33 non-serrated crypt focus was $B R A F$-mutant [53]. Another study examined intestinal adenoma, and found $B R A F$ mutations in all (9/9) dysplastic serrated adenomas and also in 18/50 (36\%) hyperplastic polyps characterized by elongated crypts [54]. In contrast to $B R A F$ mutations, $K R A S$ mutations were comparatively infrequent in serrated crypt foci $(3 / 16)$, absent in dysplastic serrated adenoma (0/9), but present in 9/50 hyperplastic polyps $[53,54]$. Recent studies confirmed and extended these results using genomic profiling [55]. In line with the data from human precancerous lesions, several mouse models of activated MAPK signaling display serrated intestinal hyperplasia or dysplasia: overexpression of EGF ligand results in serrated polyp formation in the cecum [56], and inducible knock-in $K R A S(G 12 D)$ mice develop serrated hyperplasia of the small and large intestine [57-59]. Likewise, activation of oncogenic BRAF in the intestine results in formation of generalized serrated hyperplasia $[60,61]$. Analysis of $B R A F$-mutant foci progressing via dysplastic stages to low- and highgrade carcinoma revealed a preferred sequence of events in mouse serrated tumor progression [61]: following the initiating $B R A F$ mutation, MAPK activity was only mildly enhanced. Advanced dysplastic foci contained further mutations that activated the $\mathrm{Wnt} / \beta$-catenin pathway, such as activating mutations in $C t n n b 1$ (coding for $\beta$-Catenin), or inactivating mutations in the negative Wnt regulators $A p c$ or Lrp 1b. These together with the initiating $B R A F$ mutation and possibly further genomic alterations resulted in a hyperactivation of both Wnt and MAPK signals. This progression sequence for murine serrated adenoma is in line with data from human sessile serrated adenoma, which also displays both $B R A F$ mutations and nuclear $\beta$-Catenin $[62,63]$.

Several key lessons can be learned from the collective studies of human CRC progression and mouse models. Firstly, oncogenic $K R A S$ is a key factor in the progression of conventional adenoma by synergizing with the initiating functional loss of $A P C$. Secondly, both oncogenic $B R A F$ and $K R A S$ can act as initiators in the development of CRCs arising via serrated adenoma. However, since $B R A F$ mutations are strongly associated with sessile serrated phenotypes, their individual effects as tumor initiators in the intestinal epithelium are clearly different. Thirdly, the observation of nuclear $\beta$-catenin in serrated adenomas that arise via $B R A F$ mutations strongly suggests that high $\mathrm{Wnt} / \beta$-catenin activity is favored at an early stage of serrated tumor progression via mechanisms yet unknown in human CRC. The TCGA database provides a rich source of such alterations (such as SNPs, gene fusions and copy number alterations), and reveals that $B R A F$-mutated tumors are associated with multiple mutations in Wnt pathway-associated genes such as $A X I N 1, C D X 2, S O X 9, F B X W 7, T C F 7 L 1 / 2$ and $R S P O 1 / 2$ [64]. The co-occurrence between mutations in $B R A F$ and $F B X W 7$ is significant ( $p$-value $<0.001$; survey TCGA, May 2015), indicating that mutated $B R A F$ preferentially co-operates with distinct Wnt signal modulators (Fig. 1). In contrast to conventional adenoma, mutations in $A P C$ are an exception rather than the rule in the developmental pathway of serrated adenoma driven by BRAF [65].

A further important observation from mouse models and human CRC is that mutations activating KRAS and BRAF do not necessarily result in tumor formation in the intestinal epithelium, due to the existence of failsafe mechanisms suppressing tumor growth after MAPK activation. In humans, this is evidenced by the existence of many serrated aberrant crypt foci, which are dormant and do not progress [53]. In mice, oncogenic activation via knock-in $K R A S$ and $B R A F$ alleles has likewise been associated with the induction of oncogene-induced senescence in some [59, 60], but not all [48, 58, 61, $66]$ models, suggesting that the response to oncogenic MAPK signals is highly context-dependent. In oncogenic $K R A S$ as well as in $B R A F$ mouse models, cells could escape senescence following the deletion of p16INK4a or p53 $[59,60]$, and these mutations are also frequent in human CRC. It thus appears that tumor initiation and/ or progression by KRAS or BRAF not only depends on mutational activation in the tumor-initiating cell, but also on successful evasion of common tumor suppressing mechanisms in the mutated clone. 


\section{KRAS and BRAF differentially regulate cellular hierarchies, stem cell function and CRC development}

Recent studies in mice have unveiled distinct effects of $K R A S$ and $B R A F$ oncogenes on cellular hierarchies in the normal intestinal epithelium. For instance, both oncogenic KRAS and BRAF can direct differentiation towards secretory Goblet cells in the mouse intestine [58, 61, 67]. Furthermore, both oncogenes were found to affect stem cell fate: using clonal analyses, two studies have noted that the progeny of intestinal stem cells expressing oncogenic $K R A S$ expands within and beyond single crypts by modulating asymmetric stem cell division $[68,69]$. It is of note that the stem cell pool does not necessarily expand while the KRAS mutation spreads in the tissue, due to further and poorly defined mechanisms sustaining stem cell homeostasis at the crypt level [67]. Furthermore, the formation of ectopic stem cells in the differentiated villus tissue has been observed after activation of $K R A S(G 12 D)$ in the intestine of mice [70]. In contrast to this, we found that generalized transgenic expression of oncogenic $B R A F$ in the intestine results in a rapid depletion of the entire stem cell pool, which adopts progenitor fate [71]. A reduction of intestinal stem cell markers is also found in hyperplastic intestinal tissue of $B R A F(V 637 E)$ knockin mice [61]. It therefore appears that the KRAS and the $B R A F$ oncogenes modulate signaling networks controlling homeostasis and stem cell competition in the intestinal crypt in an opposing manner. Side-by-side studies using comparable genetically engineered mouse models will be required to ascertain these effects, which could shed light on different selective constraints that KRASversus BRAF- mutant cells have for tumor initiation and progression in the intestinal epithelium.

In agreement with the possibility of differential functional roles of oncogenic $K R A S$ and $B R A F$ mutations during early stages of tumor development, significant correlations with molecular and clinical features have been identified (Fig. 2). In particular, CRCs with mutant $B R A F$ are characterized by specific genetic and epigenetic features $[11,65,72-75]$. On the level of the epigenome, $B R A F$-mutant CRCs and their (serrated) precursors often display genome-wide hypermethylation of $\mathrm{CpG}$ islands (CpG Island Methylator Phenotype: CIMP-high). A recent study suggests that the association between mutant

\section{Conventional Pathway}

\section{Serrated Pathways}

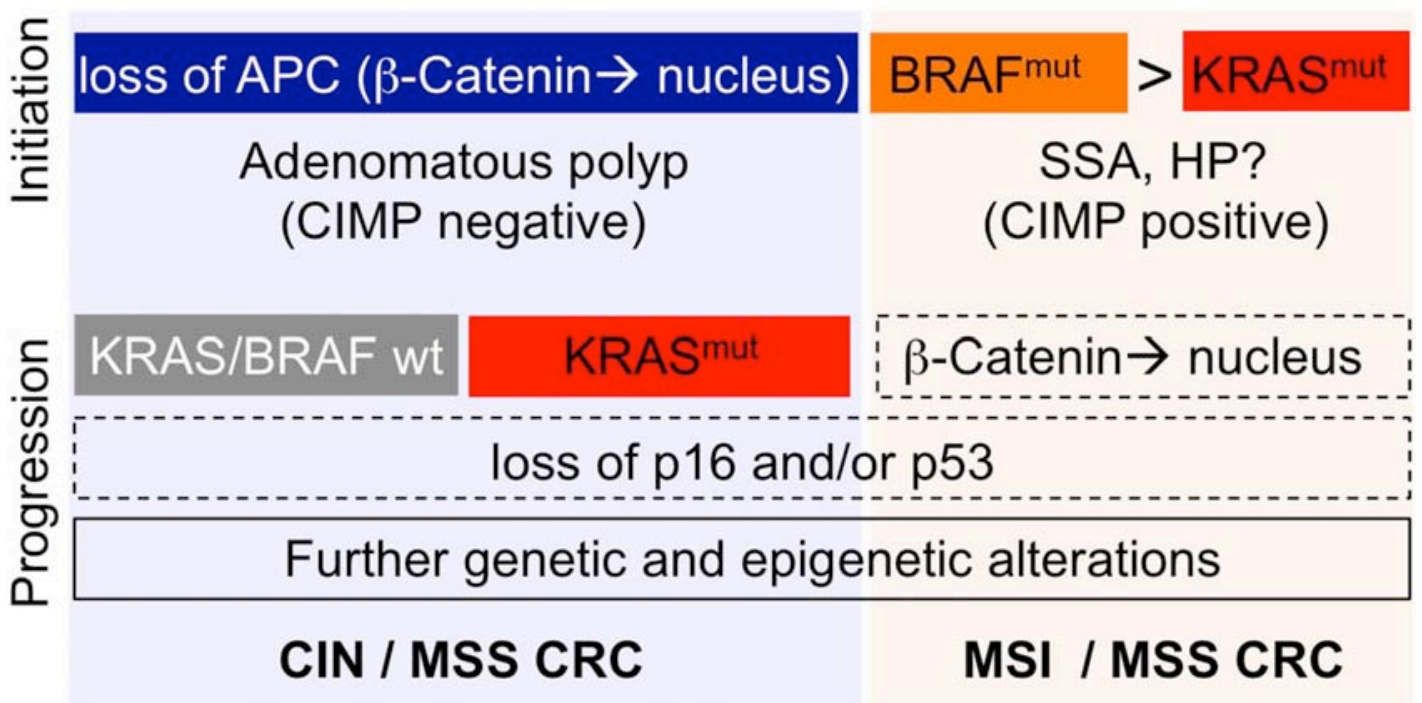

Figure 2: Roles of KRAS (red) and BRAF (orange) in distinct progression pathways of CRC. A majority (70-80\%) of CRCs initiate via APC mutations (blue) and develop via conventional adenomatous polyps (to the left) that show no or low methylation of $\mathrm{CpG}$ islands (CIMP-negative/low). KRAS, but not BRAF, mutations are frequent in this group. CRC developing via this route are associated with microsatellite-stability (MSS) and chromosomal instablity (CIN). A minority (20-30\%) of CRCs initiates via BRAF or KRAS mutations and develop via serrated adenoma precursors (to the right). Sessile-serrated adenoma (SSA) is highly associated with BRAF mutations. The malignant potential of hyperplastic polyps (HP) is not well defined. BRAF-mutant SSA frequently shows nuclear $\beta$-Catenin, but APC mutations are rare. Serrated tumors, in particular these with BRAF mutations, often show strong methylation of CpG islands (CIMP-high). CRC forming via the BRAF/SSA pathway are microsatellite-stable or microsatellite-instable (MSS/MSI). It is of note that the diagram summarizes only major correlations between molecular and clinical features. APC, BRAF and KRAS mutations are given in blue, yellow and red. Further genetic and epigenetic alterations arising during tumor progression are outlined. Dashed boxes indicate events that are frequent but not mandatory in the progression pathway. Precursor lesions and prevalent methylation phenotypes are given below the initiating mutations. The most common molecular CRC types are given in bold, below the progression pathways. 
$B R A F$ and CIMP-high is due to the phosphorylation of the transcriptional co-repressor MAFG via the BRAF-MEKERK axis. Subsequently, complexes of phosphorylated MAFG, BACH1 and the epigenetic modifiers CHD8 and DNMT3B are recruited to $\mathrm{CpG}$ islands, resulting in focal DNA hypermethylation and transcriptional silencing of nearby genes [76]. BRAF-mutant CRCs are also characterized by mismatch-repair deficiency, high levels of microsatellite instability (MSI-H) and very high overall mutation rates ( $>12$ mutations per $10^{6}$ nucleotides) [22] Clinically, $B R A F$ mutations are associated with infiltration of lymphocytes, localization in the proximal/right colon, occurrence in female patients, poor differentiation, mucinous (i.e. Goblet-cell rich) type. The association with these features is well explained by the overlap of $B R A F$ mutations with microsatellite instability (MSI-H), a common finding in the serrated pathway of colorectal cancer. BRAF mutations have also been associated with poor survival, but this phenomenon is restricted to carcinomas not showing microsatellite instability [75]. In contrast, KRAS mutations are more frequent in CRCs of the left colon and in male patients. KRAS mutations are associated with microsatellite-stability (MSS) or low levels of microsatellite-instability (MSI-L), and lower rates of gene methylation (CIMP-negative or low). Frequencies of $B R A F$ and $K R A S$ mutations, as well as rates of CIMP and MSI form continuous gradients along the longitudinal axis of the gut $[77,78]$. This suggests that CRC does not emerge as distinct subtypes that occur strictly in the different parts of the colon and rectum. Indeed, rectal cancer matches colon cancer regarding most of its molecular features [11], but has a lower incidence of $B R A F$ mutations and patients may have individual clinical requirements $[79,80]$. More recently, integrated unsupervised analyses of genetic and epigenetic traits have supported the idea that distinct classes of CRCs exist along borders defined by gene expression, genome stability (such as MSI/MSS), epigenetic make-up (such as-CIMP high/low/negative) and $B R A F / K R A S$ mutational status $[11,81-83]$. In these classifications, CRCs with $K R A S$ or $B R A F$ mutations are regularly enriched in different classes, highlighting their different evolutionary histories and distinct wiring of signaling networks.

\section{Similar and distinct roles of BRAF and KRAS in signal transduction and therapeutic intervention}

During tumor progression, genetic (and epigenetic) alterations accumulate in an evolutionary manner via consecutive cycles of mutation and selection. Multiple mutations ultimately contribute to the formation of an oncogenic network sustaining the transformed cancer phenotype. In the oncogenic signal networks of advanced CRC, mutated KRAS and BRAF have been shown to serve many functions beyond maintaining cellular proliferation, stemness and growth factor-independent growth. Indeed, both oncoproteins have been shown to contribute to angiogenesis, cell differentiation, epithelial-mesenchymal transition, adaptations of cellular metabolism and circadian rhythm networks, and many further traits of tumor cells. [3, 4, 84-87]. Due to the complex patterns of interdependent driver mutations, cancer cells frequently become dependent on certain oncogenic signals such as for oncogenic KRAS in CRC [88]. This phenomenondesignated as "oncogene addiction" - opens a therapeutic window for the specific targeting of cancer [89, 90]. The essential role of the hyperactivated EGFR-KRAS-BRAF signaling cascade in CRC has spurred the development of therapeutic approaches to inhibit the cascade on several levels, specifically targeting EGFR, KRAS and BRAF (Fig. 3, Table 1). KRAS itself, being a small GTPase, has proven to be largely "undruggable" to date, despite recent promising developments [91].

Inhibition of the transmembrane tyrosine kinase receptor EGFR has proven to be beneficial for a considerable subset of patients with metastatic CRC. Upon treatment with EGFR-inhibiting antibodies such as Cetuximab or Panitumumab, patients showed an overall survival benefit of 3-5 months when the cancer was wildtype for $K R A S$, but no benefit when the cancer was $K R A S$-mutated [92-94]. Therefore, $K R A S$, and now also $N R A S$ mutations are considered negative predictive markers for anti-EGFR therapy. Presently, Cetuximab and Panitumumab are recommended as first-line therapy in combination with chemotherapy for patients with wildtype configurations in $K R A S$ and $N R A S$ according to European (ESMO) and American (AJCC) standards. Other targeted therapies currently available in clinical routine, such as the VEGF inhibitor Bevazicumab, seem to act independently of both KRAS and BRAF [95].

In contrast to the $R A S$ mutations, mutant $B R A F$ has not been identified as an independent predictive marker for first-line anti-EGFR therapy in a dedicated clinical study. This is most likely due to the fact that $B R A F$ mutations occur at rather low frequencies and thus no clinical study harbors enough patients to reach statistical significance. Furthermore, patients with $B R A F$ mutations, in particular these with $B R A F / M S S$, have a poor outcome, which is independent of the applied therapy [75] [95]. However, a recent meta-analysis investigating the outcome of more than 400 RASwt/BRAFmut patients from 10 different trials clearly showed that patients harboring $B R A F$ mutations do not benefit from EGFR-directed therapy and thus should be tested prior to the administration of either Cetuximab or Panitumumab [96].

It is important to note that even responders to antiEGFR therapy routinely develop secondary resistance during anti-EGFR therapy, often by selection of KRAS/ $N R A S$ or $B R A F$-mutant clones arising from a RASwildtype cancer [97-99]. Indeed, mathematical modeling has suggested that targeted monotherapy will invariably lead to the selection of resistant cells once a cancer has 


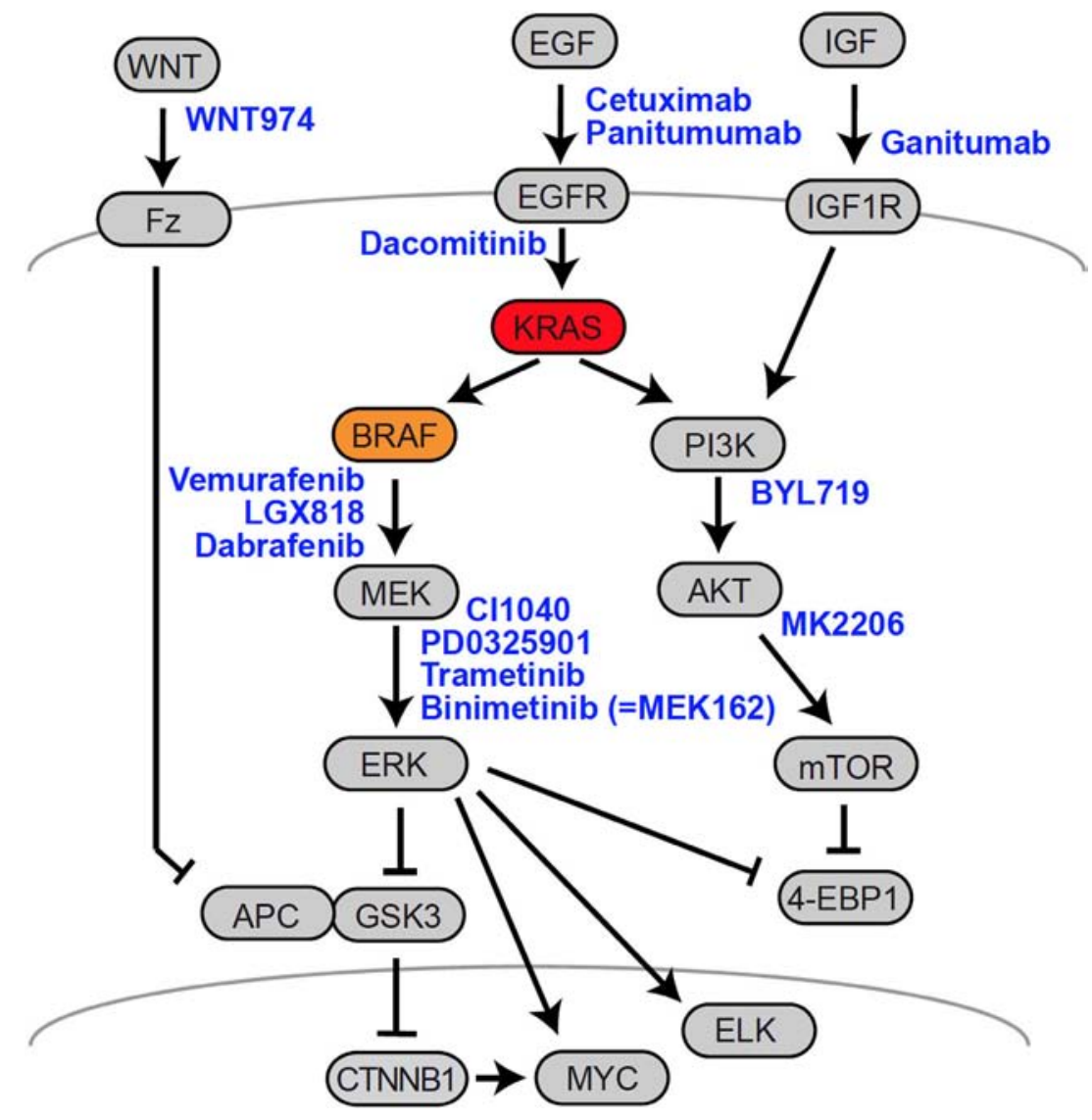

Figure 3: Therapeutic targets in CRC. A schematic representation of the EGFR-RAS-MAPK, PI3K and Wnt-APC- $\beta$-Catenin signaling axes is given, along with therapeutics used in clinical studies. Arrows indicate important connections between the signaling molecules. Drugs are given in blue, next to their targets. Names of proteins frequently refer to a representative member of a multiprotein family. For further details, see main text. For a list of clinical studies, see Table 1.

grown beyond a certain size [100]. Interestingly, a recent CRC progression model suggested that clonal evolution of CRC is constrained by the organization of the cancer into distinct glandular crypts, effectively reserving evolutionary sweeps in the advanced disease to rare events such as metastasis and the emergence of therapy resistance $[101,102]$. Therefore, anti-EGFR therapy could aid the expansion of KRAS- or BRAF-mutant clones that would be contained in a local niche in the absence of therapy.

It appears to be a rational strategy to target mitogenic signaling downstream of mutated $K R A S$ and $B R A F$, since both mutations are prevalent in primary and resistant CRC and the mutations have a negative predictive and prognostic value. However, inhibition of oncogenic BRAF(V600E) using Vemurafenib, or of the MEK kinase using CI1040, has proven to be ineffective in CRC [103, 104]. The major reason for this disappointing outcome of kinase inhibition within the MAPK kinase cascade is the existence of multiple levels of feedback control, and regulatory intersections with further pathways such as PI3K-AKT.

Indeed, several levels of feedback exist between the RAF-MEK-ERK axis and upstream receptor tyrosine kinases such as EGFR (Fig. 4): firstly, active ERK phosphorylates EGFR and EGFR signaling adaptor molecules at inhibitory residues, thus keeping signal transduction of the ligand-bound receptor to RAS in check [105-107]. Secondly, ERK activity induces transcription of SPRY family feedback inhibitors that likewise control signal transduction from receptors to RAS proteins [108]. These levels of feedback limit growth factor-induced MAPK activation in the normal tissue. In CRC cells with constitutive MAPK activity, feedbacks converging on receptor tyrosine kinases are inactivated once MEK is inhibited. Thus, receptors including EGFR become activated under MEK blockade, triggering multiple downstream pathways such as MAPK and the PIK3CAAKT-mTOR signaling axis (Fig. 4). In addition it has been found that the EGFR family member gene ERBB3 is upregulated by the transcription factor c-Myc upon MEK inhibition, suggesting further feedback control on the transcriptional level [109]. In line with negative transcriptional and posttranslational control of EGFR signals via ERK, recent siRNA screens and systems biology approaches have revealed that EGFR signal re-activation plays an important role in resistance to MEK blockade in CRC cells [110, 111]. In addition, 
Table 1: Clinical studies employing targeted combination therapies for the treatment of advanced CRC with specific mutation patterns

\begin{tabular}{|c|c|c|c|c|}
\hline Study Identifier & $\begin{array}{l}\text { Condition } \\
\text { (Mutations) }\end{array}$ & Intervention & Primary Outcome & Phase \\
\hline NCT01791309 & BRAF(V600E) CRC & $\begin{array}{l}\text { Vemurafenib } \\
\text { Panitumumab }\end{array}$ & ORR & Pilot \\
\hline NCT01719380 & BRAF-mut CRC & \begin{tabular}{|l} 
LGX818 \\
Cetuximab \\
BYL719 \\
\end{tabular} & Toxicity, PFS & $\mathrm{I} / \mathrm{II}$ \\
\hline NCT01750918 & BRAF(V600E) CRC & $\begin{array}{l}\text { Dabrafenib } \\
\text { Trametinib } \\
\text { Panitumumab } \\
\text { 5-fluorouracil }\end{array}$ & Safety, RR, PFS & $\mathrm{I} / \mathrm{II}$ \\
\hline NCT02278133 & $\begin{array}{l}\text { BRAF-mut CRC + } \\
\text { upstream Wnt pathway } \\
\text { activation }\end{array}$ & $\begin{array}{l}\text { WNT974 } \\
\text { LGX818 } \\
\text { Cetuximab }\end{array}$ & Toxicity, ORR & $\mathrm{Ib} / \mathrm{II}$ \\
\hline NCT01562899 & KRAS-mut CRC & $\begin{array}{l}\text { MEK162 } \\
\text { Ganitumab }\end{array}$ & Toxicity, ORR & $\mathrm{Ib} / \mathrm{II}$ \\
\hline NCT02039336 & KRAS-mut CRC & $\begin{array}{l}\text { Dacomitinib } \\
\text { PD0325901 }\end{array}$ & Toxicity, PFS & $\mathrm{I} / \mathrm{II}$ \\
\hline NCT02399943 & RAS/RAF-wt CRC & $\begin{array}{l}\text { Panitumumab } \\
\text { Trametinib }\end{array}$ & Response & II \\
\hline
\end{tabular}

For detailed information, refer to http:/www.clinicaltrials.gov. For therapeutic targets, see Fig. 3. CRC = colorectal cancer; $\mathrm{ORR}=$ overall response rate; $\mathrm{PFS}=$ progression-free survival; $\mathrm{RR}=$ response rate.

ERK activity controls MAPK signals via mechanisms that provide feedback downstream of RAS. This level of control is exerted directly via inhibitory phosphorylation of RAF-1 by ERK [112], and also via transcriptional activation the DUSP family of phosphatases that dephosphorylate and therefore inactivate ERK [113]. Of the various layers of feedback control, the prevalent mechanism in CRC cells appears to be strong negative feedback from ERK1/2 to RAF [114]. Feedback activation of EGFR and RAF have also been identified as important mechanisms to mediate drug resistance following RAF or MEK inhibition [99, 110, 115-117].

The disappointing results achieved using the BRAF(V600E)-specific inhibitor Vemurafenib in CRC patients not only showed the importance of these feedbacks in vivo, but also demonstrated the different wiring of oncogenic networks in cancers of either neuroectodermal or epithelial origin such as melanoma and $\mathrm{CRC}$, respectively. This led to the development of preclinical treatment schemes that appear counterintuitive, but take into account the feedback-controlled organization of oncogenic networks that can only be controlled by simultaneous treatment with multiple drugs. Preclinical studies suggested improved antitumor activity when BRAF inhibition was employed in combinatorial treatment [118]. Currently, several pilot trials and clinical studies aim at simultaneously inhibiting EGFR and BRAF or MEK for treatment of BRAF-mutant (or KRAS-mutant) CRC patients, in order to block both, the oncogenic RAFMEK-ERK signal, as well as the feedback loop via EGFR family members (Fig. 3, Table 1). First results suggest that a limited clinical response exists in patients that have failed in first-line therapies [119-124]. However, patients who received EGFR-MEK-BRAF combination therapies can also relapse with novel genetic alterations conferring resistance through sustained MAPK activity, such as amplification of KRAS or BRAF or, in one case, a mutation in the downstream kinase MEK1 [125]. It is indeed expected that combination therapies converging on a common (downstream) signaling pathway are prone to the development of therapy resistance [100].

It is important to note that KRAS- versus BRAFmutant CRCs likely display characteristic differences in response to therapeutic interference in the MAPK cascade, due to mechanistic differences in signal transduction (Fig. 4). For one, BRAF mutations disallow the critical feedback from ERK to RAF to occur, while KRAS mutations leave this feedback intact [114]. As a consequence, higher levels of MEK inhibitor are required in KRAS mutated CRC cells as compared to BRAF mutated cells to suppress MEK/ERK activation. Furthermore, highlighting an important difference between KRAS- and BRAF-mutant cancer cells, ATP-competitive RAF inhibitors were found to block 


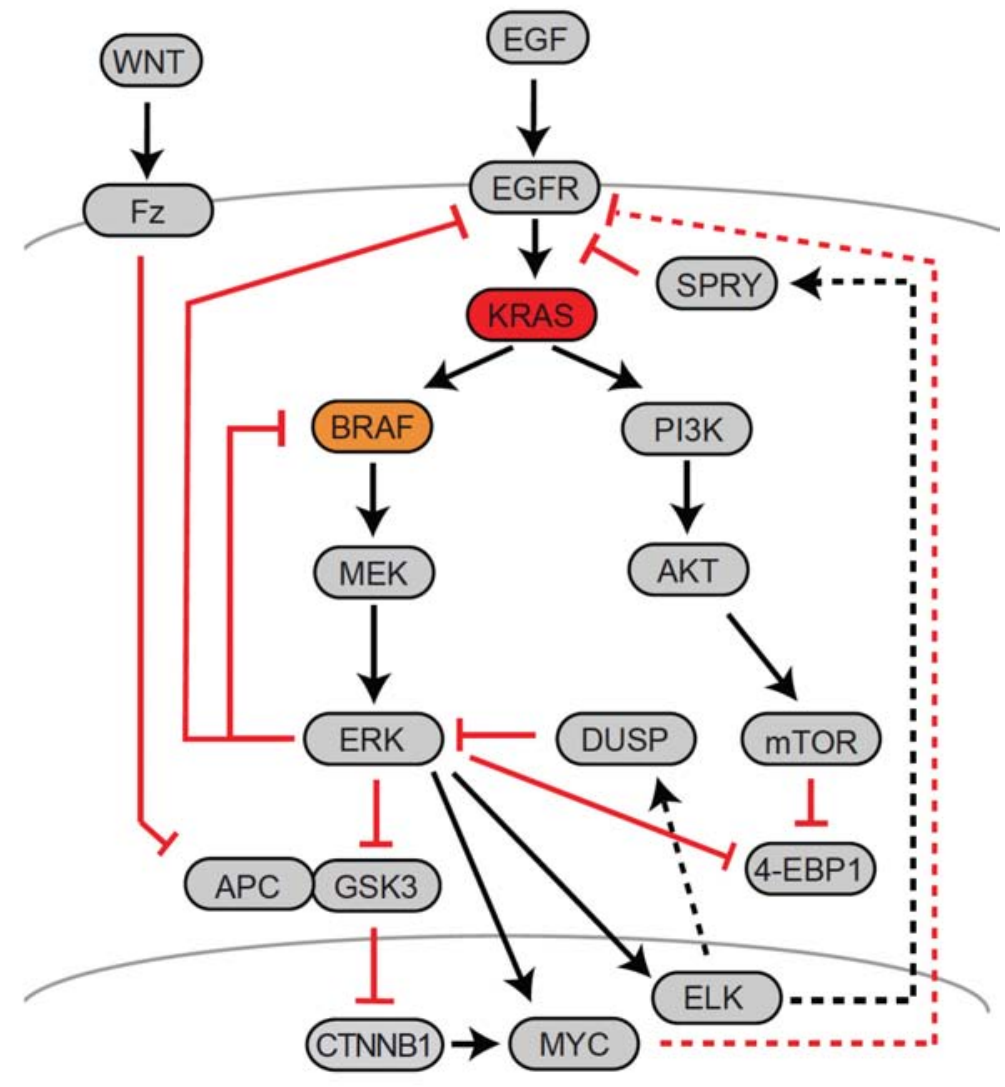

Figure 4: Major feedback mechanisms controlling MAPK activity in CRC. A schematic representation of the EGFR-RASMAPK, PI3K and Wnt-APC- $\beta$-Catenin signaling axes is given, along with signaling connections. Major positive interactions are given as black arrows, while inhibitory interactions are given as red blocked lines. Solid lines indicate molecular interactions, whereas dotted lines indicate transcriptional control. Names frequently refer to a representative member of a multiprotein family.

MEK-ERK signal transduction in BRAF-mutant cancer cells, but unexpectedly activated MEK-ERK signaling in cancer cells harboring mutant RAS and wildtype BRAF [126-128]. On a molecular level, this paradoxical activation could be explained by different propensities of BRAF and RAF-1 to form homo- versus heterodimers $[4,129]$. It was also found that inhibition of active MEK has different constraints downstream of oncogenic KRAS versus BRAF [130]: while KRAS-driven cancer cells are sensitive towards inhibitors interacting with MEK-Serine212 (a site critical for feedback between MEK and wildtype BRAF), BRAF-mutant cancer cells required another class of MEK inhibitor that blocks phosphorylated active MEK. Taken together, the aforementioned studies underline the necessity to develop specific and effective diagnostics and therapies for patients with $B R A F$ mutated CRC. An unusual approach to exploit specific traits of BRAF-mutated cells was recently presented by exploiting the finding that synthesis of BRAF is dependent on chaperone action. Thus, interference with the BRAF chaperone TRAP1 was shown to effectively inhibit proliferation of $B R A F$ mutated CRC cells [131].
Finally, it is necessary to expand the view beyond the EGFR-RAS-RAF-MEK-ERK cascade to appreciate interactions within the larger signaling network and cover specific signaling properties of the oncogenes. As outlined above, feedback via EGFR is suited to activate PIK3CAAKT signals upon MAPK blockade. In this regard, it is important that the PIK3CA-AKT-mTOR axis is frequently activated either by loss of PTEN or activation of PIK3CA in CRC, independent of the KRAS or BRAF status [132]. Furthermore, the RAF-MEK-ERK and PIK3CAAKT-mTOR cascades converge on important common substrates, such as 4EBP1 and eIF4F, controlling protein translation, cell survival and ultimately therapy resistance $[133,134]$. Therefore, novel combination therapies currently in clinical trials seek to inhibit the EGFRRAS-RAF-MEK-ERK and PIK3CA-AKT cascades in parallel, for instance by combining Cetuximab, LGX818 and the PI3K inhibitor BYL719 in patients with BRAF mutations [135] (Fig. 3, Table 1). These strategies seem to be promising, given that both oncogenic pathways have common targets that only respond to the parallel inhibition of RAS-RAF-MEK and PIK3CA-AKT [133]. Indeed, concurrent inhibition of BRAF and PIK3CA/mTOR 
induced tumor regression in a BRAF-mutant CRC mouse model [136]. Adding another twist to the story, mTOR4EBP1 signals are also controlled via the Wnt-APC- $\beta$ Catenin axis in the intestinal epithelium [137], providing yet another important convergence point of key signaling pathways. Simultaneous inhibition of Wnt and MAPK signals is currently in clinical testing for the treatment of a subset of BRAF-mutant CRC patients, employing Cetuximab, LGX818 and the Wnt ligand maturation inhibitor WNT974 [138](Fig. 3, Table 1). Recent preclinical studies suggest a role for the Hippo signal transducer YAP in resistance to RAF and MEK inhibition in multiple cancer cell lines, including BRAF-mutant CRC. These findings may provide another strategy for the design of combinatorial targeted therapies [139, 140].

Future models of tumor development and therapeutic intervention may also need to integrate the activities of soluble factors providing autocrine or paracrine interactions between different cells types that compose the tumor. Already in 2001, Schulze et al. described a positive autocrine feedback loop induced by RAF via the EGFR ligand HB-EGF [141]. KRAS-mutant CRC cells can also activate a positive loop via TGF-alpha, one of the strongest EGFR activators, which in turn results in the activation of a CXCL1/CXCL8-dependent autocrine signal [142]. Paracrine interactions between tumor and stromal cells have also been identified. RAF inhibitors were found to elicit innate resistance via secretion of the growth factor HGF by stromal cells, resulting in ERK and PI3K-AKT activation and therapy resistance [143]; these results suggest a potential for the concurrent application of RAF and HGF/ MET inhibitors in CRC and other cancers. Furthermore, a major part of the gene expression differences between goodand poor-prognosis CRC were found to arise from TGF- $\beta$ signals in cancer-associated fibroblasts [144]. Importantly, the blockade of TGF- $\beta$ signals stopped CRC progression in in-vitro and xenograft models. Further expanding the idea of cellular and clonal co-operation in cancer, recent data from breast cancer suggests the existence of tumor cell subclones that can cooperate with stromal cells to support cancer growth via secreted factors [145]. While no comprehensive data on secreted factors determined by KRAS or BRAF oncogenes are available in CRC, this might comprise a further molecular level of specificity determining both the distinct roles of KRAS and BRAF in tumor progression and therapy response.

A recent study reported improved antitumor response in a mouse model of melanoma using BRAF and MEK inhibitors in combination with immunotherapy [146]. Such improved therapeutic applications are currently not available for $K R A S$ - and $B R A F$-mutated $\mathrm{CRC}$, however we have previously described a reversible negative impact of the KRAS oncogene and activated MAPK signaling onto MHC-I expression in CRC cells [147]. A recent publication confirmed a significant association between MHC-I loss and KRAS mutations, but not BRAF mutations, in CRC [148]. Consequently, similar to the observations in melanoma, the development of combinatorial treatment using BRAF and/or MEK inhibitors with immunotherapy appears to hold promise for CRC patients. However, an improved knowledge of underlying mechanisms and the plasticity of the contributing factors upon therapeutic interference is required.

\section{Outlook}

Since the discovery of mutated forms of KRAS and BRAF as mutually exclusive drivers of colorectal carcinogenesis, much progress has been made in understanding their common and individual effects. Inhibition of oncogenic signals originating from KRAS and BRAF has a high priority in CRC research. However, inhibition of single nodes within the intracellular kinase networks associated with KRAS and BRAF typically resulted in drug resistance and therapy failure. Studies of human cancer specimens, cells and mice suggest that resistance to inhibitors is usually due to feedback and crosstalk mechanisms that allow transduction of oncogenic signals in spite of blockade of a single network node. In addition, inadvertent selection of resistant clones with novel combinations of oncogenic mutations can occur under monotherapy or combination therapy that allows for single mutation to confer drug resistance. Therefore, a better understanding of the BRAF and KRAS-specific wiring of the MAPK signaling network is required for the development of new combinatorial therapeutic options.

Yet the impact that oncogenic KRAS and BRAF have on CRC development stretches out beyond their roles as signaling molecules. It can be inferred from their similar but subtly different roles during tumor initiation that KRAS and BRAF are also defining factors influencing cancer development. This probably occurs via modulation of signaling networks impinging on the epigenome and mutation-specific constraints of signaling networks that dictate clonal selection. It will therefore be important to differentiate CRCs beyond the mutational status of BRAF and KRAS by further defining selective advantages and limitations of KRAS- and BRAF-mutant cells in a tissue context in order to understand their clonal histories and co-selected vulnerabilities. Thus, analysis of tumor evolution in combination with a better understanding of oncogenic signaling networks will provide cues to derive novel predictive markers and therapy options.

\section{ACKNOWLEDGMENTS}

The authors gratefully acknowledge funding by German Ministry of Education and Research (e:Bio OncoPath 0316184A to CS and MM; DKTK to CS) and Deutsche Forschungsgemeinschaft (MO 2783/2-1 to MM).

\section{CONFLICTS OF INTEREST}

No conflict of interest to be declared. 


\section{REFERENCES}

1. Hanahan D, Weinberg RA. Hallmarks of cancer: the next generation. Cell. 2011; 144:646-74.

2. Oikonomou E, Koustas E, Goulielmaki M, Pintzas A. BRAF vs RAS oncogenes: Are mutations of the same pathway equal? Differential signalling and therapeutic implications. Oncotarget. 2014; 5:11752-77.

3. Pylayeva-Gupta Y, Grabocka E, Bar-Sagi D. RAS oncogenes: weaving a tumorigenic web. Nat Rev Cancer. 2011; 11:761-74.

4. Röring M, Brummer T. Aberrant B-Raf Signaling in Human Cancer-10 Years from Bench to Bedside. Critical Reviews in Oncogenesis. 2012; 17:97-121.

5. Castellano E, Downward J. RAS Interaction with PI3K: More Than Just Another Effector Pathway. Genes Cancer. 2011; 2:261-74.

6. Bos JL, Fearon ER, Hamilton SR, Verlaan-de Vries M, van Boom JH, van der Eb AJ, et al. Prevalence of ras gene mutations in human colorectal cancers. Nature. 1987; 327:293-7.

7. Forrester K, Almoguera C, Han K, Grizzle WE, Perucho M. Detection of high incidence of K-ras oncogenes during human colon tumorigenesis. Nature. 1987; 327:298-303.

8. Vogelstein B, Fearon ER, Hamilton SR, Kern SE, Preisinger AC, Leppert M, et al. Genetic alterations during colorectal-tumor development. N Engl J Med. 1988; 319:525-32.

9. Forbes SA, Beare D, Gunasekaran P, Leung K, Bindal N, Boutselakis H, et al. COSMIC: exploring the world's knowledge of somatic mutations in human cancer. Nucleic Acids Res. 2015; 43:D805-11.

10. Gao J, Aksoy BA, Dogrusoz U, Dresdner G, Gross B, Sumer SO, et al. Integrative analysis of complex cancer genomics and clinical profiles using the cBioPortal. Sci Signal. 2013; 6:pl1.

11. Cancer Genome Atlas Network . Comprehensive molecular characterization of human colon and rectal cancer. Nature. 2012; 487:330-7.

12. Scheffzek K, Ahmadian MR, Kabsch W, Wiesmüller L, Lautwein A, Schmitz F, et al. The Ras-RasGAP complex: structural basis for GTPase activation and its loss in oncogenic Ras mutants. Science. 1997; 277:333-8.

13. Scheidig AJ, Burmester C, Goody RS. The pre-hydrolysis state of p21(ras) in complex with GTP: new insights into the role of water molecules in the GTP hydrolysis reaction of ras-like proteins. Structure. 1999; 7:1311-24.

14. Buhrman G, Holzapfel G, Fetics S, Mattos C. Allosteric modulation of Ras positions Q61 for a direct role in catalysis. Proc Natl Acad Sci USA. 2010; 107:4931-6.

15. Andreyev HJ, Norman AR, Cunningham D, Oates J, Dix BR, Iacopetta BJ, et al. Kirsten ras mutations in patients with colorectal cancer: the "RASCAL II" study. Br J Cancer. 2001; 85:692-6.

16. Bazan V, Migliavacca M, Zanna I, Tubiolo C, Grassi N, Latteri MA, et al. Specific codon K-ras mutations are predictive of clinical outcome in colorectal cancer patients, whereas codon $12 \mathrm{~K}$-ras mutations are associated with mucinous histotype. Ann Oncol. 2002; 13:1438-46.

17. Grabocka E, Pylayeva-Gupta Y, Jones MJK, Lubkov V, Yemanaberhan E, Taylor L, et al. Wild-type H- and N-Ras promote mutant K-Ras-driven tumorigenesis by modulating the DNA damage response. Cancer Cell. 2014; 25:243-56.

18. Davies H, Bignell GR, Cox C, Stephens P, Edkins S, Clegg S, et al. Mutations of the BRAF gene in human cancer. Nature. 2002; 417:949-54.

19. Wan P, Garnett MJ, Roe SM, Lee S, Niculescu-Duvaz D, Good VM, et al. Mechanism of activation of the RAF-ERK signaling pathway by oncogenic mutations of B-RAF. Cell. 2004; 116:855-67.

20. Corcoran RB, Dias-Santagata D, Bergethon K, Iafrate AJ, Settleman J, Engelman JA. BRAF gene amplification can promote acquired resistance to MEK inhibitors in cancer cells harboring the BRAF V600E mutation. Sci Signal. 2010; 3:ra84.

21. Little AS, Balmanno K, Sale MJ, Newman S, Dry JR, Hampson M, et al. Amplification of the driving oncogene, KRAS or BRAF, underpins acquired resistance to MEK1/2 inhibitors in colorectal cancer cells. Sci Signal. 2011; 4:ra17.

22. Rajagopalan H, Bardelli A, Lengauer C, Kinzler KW, Vogelstein B, Velculescu VE. Tumorigenesis: RAF/RAS oncogenes and mismatch-repair status. Nature. 2002; 418:934.

23. Irahara N, Baba Y, Nosho K, Shima K, Yan L, DiasSantagata D, et al. NRAS mutations are rare in colorectal cancer. Diagn Mol Pathol. 2010; 19:157-63.

24. Ahearn IM, Haigis K, Bar-Sagi D, Philips MR. Regulating the regulator: post-translational modification of RAS. Nat Rev Mol Cell Biol. 2012; 13:39-51.

25. Prior IA, Hancock JF. Ras trafficking, localization and compartmentalized signalling. Semin Cell Dev Biol. 2012; 23:145-53.

26. Terai K, Matsuda M. The amino-terminal B-Raf-specific region mediates calcium-dependent homo- and heterodimerization of Raf. EMBO J. 2006; 25:3556-64.

27. Ding J, Tchaicheeyan O, Ambrosio L. Drosophila Raf's $\mathrm{N}$ terminus contains a novel conserved region and can contribute to torso RTK signaling. Genetics. 2010; 184:717-29.

28. Tran NH, Wu X, Frost JA. B-Raf and Raf-1 are regulated by distinct autoregulatory mechanisms. J Biol Chem. 2005; 280:16244-53.

29. Brummer T, Martin P, Herzog S, Misawa Y, Daly RJ, Reth M. Functional analysis of the regulatory requirements 
of B-Raf and the B-Raf(V600E) oncoprotein. Oncogene. 2006; 25:6262-76.

30. Marais R, Light Y, Paterson HF, Mason CS, Marshall CJ. Differential regulation of Raf-1, A-Raf, and B-Raf by oncogenic ras and tyrosine kinases. J Biol Chem. 1997; 272:4378-83.

31. Weber CK, Slupsky JR, Kalmes HA, Rapp UR. Active Ras induces heterodimerization of $\mathrm{cRaf}$ and BRaf. Cancer Res. 2001; 61:3595-8.

32. Ahlquist $\mathrm{T}$, Bottillo I, Danielsen SA, Meling GI, Rognum TO, Lind GE, et al. RAS signaling in colorectal carcinomas through alteration of RAS, RAF, NF1, and/or RASSF1A. Neoplasia. 2008; 10:680-686.

33. Stites EC, Trampont PC, Haney LB, Walk SF, Ravichandran KS. Cooperation between Noncanonical Ras Network Mutations. Cell Rep. 2015.

34. Min J, Zaslavsky A, Fedele G, McLaughlin SK, Reczek EE, De Raedt T, et al. An oncogene-tumor suppressor cascade drives metastatic prostate cancer by coordinately activating Ras and nuclear factor-kappaB. Nat Med. 2010; 286-94.

35. Zhang Z, Chen Y, Tang J, Xie X. Frequent loss expression of dab2 and promotor hypermethylation in human cancers: a meta-analysis and systematic review. Pak J Med Sci. 2014; 30:432-7.

36. Fearon ER, Vogelstein B. A genetic model for colorectal tumorigenesis. Cell. 1990; 61:759-67.

37. Fearon ER. Molecular genetics of colorectal cancer. Annu Rev Pathol. 2011; 6:479-507.

38. Sato T, Vries RG, Snippert HJ, van de Wetering M, Barker N, Stange DE, et al. Single Lgr5 stem cells build crypt-villus structures in vitro without a mesenchymal niche. Nature. 2009; 459:262-5.

39. Sato T, van Es JH, Snippert HJ, Stange DE, Vries RG, van den Born $\mathrm{M}$, et al. Paneth cells constitute the niche for Lgr5 stem cells in intestinal crypts. Nature. 2010; 469:415.

40. Wong VWY, Stange DE, Page ME, Buczacki S, Wabik A, Itami S, et al. Lrig1 controls intestinal stem-cell homeostasis by negative regulation of ErbB signalling. Nat Cell Biol. 2012; 14:401-8.

41. Barker N. Adult intestinal stem cells: critical drivers of epithelial homeostasis and regeneration. Nat Rev Mol Cell Biol. 2013.

42. Barker N, Ridgway RA, van Es JH, van de Wetering M, Begthel $\mathrm{H}$, van den Born $\mathrm{M}$, et al. Crypt stem cells as the cells-of-origin of intestinal cancer. Nature. 2009; 457:608-11.

43. Zhu L, Gibson P, Currle DS, Tong Y, Richardson RJ, Bayazitov IT, et al. Prominin 1 marks intestinal stem cells that are susceptible to neoplastic transformation. Nature. 2009; 457:603-7.

44. Matano M, Date S, Shimokawa M, Takano A, Fujii M, Ohta $\mathrm{Y}$, et al. Modeling colorectal cancer using
CRISPR-Cas9-mediated engineering of human intestinal organoids. Nat Med. 2015; 256-62.

45. Su LK, Vogelstein B, Kinzler KW. Association of the APC tumor suppressor protein with catenins. Science. 1993; 262:1734-7.

46. Farr CJ, Marshall CJ, Easty DJ, Wright NA, Powell SC, Paraskeva C. A study of ras gene mutations in colonic adenomas from familial polyposis coli patients. Oncogene. 1988; 3:673-8.

47. Sansom OJ, Meniel V, Wilkins JA, Cole AM, Oien KA, Marsh V, et al. Loss of Apc allows phenotypic manifestation of the transforming properties of an endogenous K-ras oncogene in vivo. Proc Natl Acad Sci USA. 2006; 103:14122-7.

48. Janssen K-P, Alberici P, Fsihi H, Gaspar C, Breukel C, Franken $\mathrm{P}$, et al. APC and oncogenic KRAS are synergistic in enhancing Wnt signaling in intestinal tumor formation and progression. Gastroenterology. 2006; 131:1096-109.

49. Phelps RA, Chidester S, Dehghanizadeh S, Phelps J, Sandoval IT, Rai K, et al. A Two-Step Model for Colon Adenoma Initiation and Progression Caused by APC Loss. Cell. 2009; 137:623-34.

50. Leggett B, Whitehall V. Role of the serrated pathway in colorectal cancer pathogenesis. Gastroenterology. 2010; pp. 2088-2100.

51. Snover DC. Update on the serrated pathway to colorectal carcinoma. Hum Pathol. 2011; 42:1-10.

52. Bettington M, Walker N, Clouston A, Brown I, Leggett B, Whitehall V. The serrated pathway to colorectal carcinoma: current concepts and challenges. Histopathology. 2013; 62:367-86.

53. Rosenberg DW, Yang S, Pleau DC, Greenspan EJ, Stevens RG, Rajan TV, et al. Mutations in BRAF and KRAS differentially distinguish serrated versus nonserrated hyperplastic aberrant crypt foci in humans. Cancer Res. 2007; 67:3551-4.

54. Chan TL, Zhao W, Leung SY, Yuen ST. BRAF, and KRAS mutations in colorectal hyperplastic polyps and serrated adenomas. Cancer Res. 2003; 63:4878-81.

55. Burnett-Hartman AN, Newcomb PA, Potter JD, Passarelli MN, Phipps AI, Wurscher MA, et al. Genomic aberrations occurring in subsets of serrated colorectal lesions but not conventional adenomas. Cancer Res. 2013; 73:2863-72.

56. Bongers $\mathrm{G}$, Muniz LR, Pacer ME, Iuga AC, Thirunarayanan N, Slinger E, et al. A role for the epidermal growth factor receptor signaling in development of intestinal serrated polyps in mice and humans. Gastroenterology. 2012; 143:730-40.

57. Tuveson DA, Shaw AT, Willis NA, Silver DP, Jackson EL, Chang S, et al. Endogenous oncogenic K-ras(G12D) stimulates proliferation and widespread neoplastic and developmental defects. Cancer Cell. 2004; 5:375-87. 
58. Haigis KM, Kendall KR, Wang Y, Cheung A, Haigis MC, Glickman JN, et al. Differential effects of oncogenic K-Ras and N-Ras on proliferation, differentiation and tumor progression in the colon. Nat Genet. 2008; 40:600-8.

59. Bennecke M, Kriegl L, Bajbouj M, Retzlaff K, Robine S, Jung A, et al. Ink4a/Arf and oncogene-induced senescence prevent tumor progression during alternative colorectal tumorigenesis. Cancer Cell. 2010 ed. 2010; 18:135-46.

60. Carragher LAS, Snell KR, Giblett SM, Aldridge VSS, Patel B, Cook SJ, et al. V600EBraf induces gastrointestinal crypt senescence and promotes tumour progression through enhanced $\mathrm{CpG}$ methylation of p16INK4a. EMBO Mol Med. 2010; 2:458-71.

61. Rad R, Cadiñanos J, Rad L, Varela I, Strong A, Kriegl L, et al. A Genetic Progression Model of Braf(V600E)Induced Intestinal Tumorigenesis Reveals Targets for Therapeutic Intervention. Cancer Cell. 2013; 24:15-29.

62. Yachida S, Mudali S, Martin SA, Montgomery EA, Iacobuzio-Donahue CA. Beta-catenin nuclear labeling is a common feature of sessile serrated adenomas and correlates with early neoplastic progression after BRAF activation. Am J Surg Pathol. 2009; 33:1823-32.

63. $\mathrm{Wu} \mathrm{JM}$, Montgomery EA, Iacobuzio-Donahue CA. Frequent beta-catenin nuclear labeling in sessile serrated polyps of the colorectum with neoplastic potential. Am J Clin Pathol. 2008; 129:416-23.

64. Krausova M, Korinek V. Wnt signaling in adult intestinal stem cells and cancer. Cell Signal. 2014; 26:570-9.

65. Jass JR. Classification of colorectal cancer based on correlation of clinical, morphological and molecular features. Histopathology. 2007; 50:113-30.

66. Janssen K-P, Marjou El F, Pinto D, Sastre X, Rouillard D, Fouquet $\mathrm{C}$, et al. Targeted expression of oncogenic K-ras in intestinal epithelium causes spontaneous tumorigenesis in mice. Gastroenterology. 2002; 123:492-504.

67. Feng Y, Bommer GT, Zhao J, Green M, Sands E, Zhai Y, et al. Mutant KRAS promotes hyperplasia and alters differentiation in the colon epithelium but does not expand the presumptive stem cell pool. Gastroenterology. 2011; 141:1003-1013.e1-10.

68. Vermeulen L, Morrissey E, van der Heijden M, Nicholson AM, Sottoriva A, Buczacki S, et al. Defining stem cell dynamics in models of intestinal tumor initiation. Science. 2013; 342:995-8.

69. Snippert HJ, Schepers AG, van Es JH, Simons BD, Clevers H. Biased competition between Lgr5 intestinal stem cells driven by oncogenic mutation induces clonal expansion. EMBO Rep. 2014; 15:62-9.

70. Schwitalla S, Fingerle AA, Cammareri P, Nebelsiek T, Göktuna SI, Ziegler PK, et al. Intestinal Tumorigenesis Initiated by Dedifferentiation and Acquisition of Stem-Celllike Properties. Cell. 2013; 152:25-38.

71. Riemer P, Sreekumar A, Reinke S, Rad R, Schäfer R, Sers C, et al. Transgenic expression of oncogenic BRAF induces loss of stem cells in the mouse intestine, which is antagonized by $\beta$-catenin activity. Oncogene. 2015; 34:3164-75.

72. Konishi K, Yamochi T, Makino R, Kaneko K, Yamamoto T, Nozawa $\mathrm{H}$, et al. Molecular differences between sporadic serrated and conventional colorectal adenomas. Clin Cancer Res. 2004; 10:3082-90.

73. Li WQ, Kawakami K, Ruszkiewicz A, Bennett G, Moore J, Iacopetta B. BRAF mutations are associated with distinctive clinical, pathological and molecular features of colorectal cancer independently of microsatellite instability status. Mol Cancer. 2006; 5:2.

74. Oliveira C, Velho S, Moutinho C, Ferreira A, Preto A, Domingo $\mathrm{E}$, et al. KRAS and BRAF oncogenic mutations in MSS colorectal carcinoma progression. Oncogene. 2007; 26:158-63.

75. Phipps AI, Limburg PJ, Baron JA, Burnett-Hartman AN, Weisenberger DJ, Laird PW, et al. Association between molecular subtypes of colorectal cancer and patient survival. Gastroenterology. 2015; 148:77-87.e2.

76. Fang M, Ou J, Hutchinson L, Green MR. The BRAF oncoprotein functions through the transcriptional repressor MAFG to mediate the $\mathrm{CpG}$ Island Methylator phenotype. Mol Cell. 2014; 55:904-15.

77. Yamauchi M, Morikawa T, Kuchiba A, Imamura Y, Qian ZR, Nishihara R, et al. Assessment of colorectal cancer molecular features along bowel subsites challenges the conception of distinct dichotomy of proximal versus distal colorectum. Gut. 2012; 61:847-54.

78. Bae JM, Kim JH, Cho N-Y, Kim TY, Kang GH. Prognostic implication of the $\mathrm{CpG}$ island methylator phenotype in colorectal cancers depends on tumour location. Br J Cancer. 2013; 109:1004-12.

79. Kohonen-Corish MRJ, Tseung J, Chan C, Currey N, Dent OF, Clarke S, et al. KRAS mutations and CDKN2A promoter methylation show an interactive adverse effect on survival and predict recurrence of rectal cancer. Int $\mathbf{J}$ Cancer. 2014; 134:2820-8.

80. Minsky BD. Unique considerations in the patient with rectal cancer. Semin Oncol. 2011; 38:542-51.

81. Shen L, Toyota M, Kondo Y, Lin E, Zhang L, Guo Y, et al. Integrated genetic and epigenetic analysis identifies three different subclasses of colon cancer. Proc Natl Acad Sci USA. 2007; 104:18654-9.

82. De Sousa E Melo F, Wang X, Jansen M, Fessler E, Trinh A, de Rooij LPMH, et al. Poor-prognosis colon cancer is defined by a molecularly distinct subtype and develops from serrated precursor lesions. Nat Med. 2013; 19:614-8.

83. Sadanandam A, Lyssiotis CA, Homicsko K, Collisson EA, Gibb WJ, Wullschleger S, et al. A colorectal cancer classification system that associates cellular phenotype and responses to therapy. Nat Med. 2013; 19:619-25.

84. Rak J, Filmus J, Finkenzeller G, Grugel S, Marmé D, Kerbel RS. Oncogenes as inducers of tumor angiogenesis. Cancer Metastasis Rev. 1995; 14:263-77. 
85. Huber MA, Kraut N, Beug H. Molecular requirements for epithelial-mesenchymal transition during tumor progression. Curr Opin Cell Biol. 2005; 17:548-58.

86. Relógio A, Thomas P, Medina-Pérez P, Reischl S, Bervoets S, Gloc E, et al. Ras-mediated deregulation of the circadian clock in cancer. PLoS Genet. 2014; 10:e1004338.

87. Herr R, Köhler M, Andrlová H, Weinberg F, Möller Y, Halbach S, et al. B-Raf inhibitors induce epithelial differentiation in BRAF-mutant colorectal cancer cells. Cancer Res. 2015; 75:216-29.

88. Shirasawa S, Furuse M, Yokoyama N, Sasazuki T. Altered growth of human colon cancer cell lines disrupted at activated Ki-ras. Science. 1993; 260:85-8.

89. Weinstein IB, Joe AK. Mechanisms of disease: Oncogene addiction - a rationale for molecular targeting in cancer therapy. Nat Clin Pract Oncol. 2006; 3:448-57.

90. Sharma SV, Settleman J. Oncogene addiction: setting the stage for molecularly targeted cancer therapy. Genes Dev. 2007; 21:3214-31.

91. Cox AD, Fesik SW, Kimmelman AC, Luo J, Der CJ. Drugging the undruggable RAS: Mission Possible? Nat Rev Drug Discov. 2014; 13:828-51.

92. Karapetis CS, Khambata-Ford S, Jonker DJ, O'Callaghan CJ, Tu D, Tebbutt NC, et al. K-ras mutations and benefit from cetuximab in advanced colorectal cancer. N Engl J Med. 2008; 359:1757-65.

93. Van Cutsem E, Köhne C-H, Hitre E, Zaluski J, Chang Chien C-R, Makhson A, et al. Cetuximab and chemotherapy as initial treatment for metastatic colorectal cancer. N Engl J Med. 2009; 360:1408-17.

94. Douillard J-Y, Oliner KS, Siena S, Tabernero J, Burkes R, Barugel M, et al. Panitumumab-FOLFOX4 treatment and RAS mutations in colorectal cancer. N Engl J Med. 2013; 369:1023-34

95. Heinemann V, Douillard JY, Ducreux M, Peeters M. Targeted therapy in metastatic colorectal cancer - An example of personalised medicine in action. Cancer Treat Rev. 2013; 39:592-601.

96. Pietrantonio F, Petrelli F, Coinu A, Di Bartolomeo M, Borgonovo K, Maggi C, et al. Predictive role of BRAF mutations in patients with advanced colorectal cancer receiving cetuximab and panitumumab: A meta-analysis. Eur J Cancer. 2015; 51:587-94.

97. Misale S, Yaeger R, Hobor S, Scala E, Janakiraman M, Liska D, et al. Emergence of KRAS mutations and acquired resistance to anti-EGFR therapy in colorectal cancer. Nature. 2012; 486:532-6.

98. Diaz LA, Williams RT, Wu J, Kinde I, Hecht JR, Berlin J, et al. The molecular evolution of acquired resistance to targeted EGFR blockade in colorectal cancers. Nature. 2012; 486:537-40.

99. Misale S, Arena S, Lamba S, Siravegna G, Lallo A, Hobor S, et al. Blockade of EGFR and MEK intercepts heterogeneous mechanisms of acquired resistance to anti-EGFR therapies in colorectal cancer. Sci Transl Med. 2014; 6:224ra26.

100. Bozic I, Allen B, Nowak MA. Dynamics of targeted cancer therapy. Trends Mol Med. 2012; 18:311-6.

101. Sottoriva A, Kang H, Ma Z, Graham TA, Salomon MP, Zhao J, et al. A Big Bang model of human colorectal tumor growth. Nat Genet. 2015; 47:209-16.

102. Robertson-Tessi M, Anderson ARA. Big Bang and context-driven collapse. Nat Genet. 2015; 47:196-7.

103. Kopetz S, Desai J, Chan E, Hecht JR, O'Dwyer PJ, Lee RJ, et al. PLX4032 in metastatic colorectal cancer patients with mutant BRAF tumors. J Clin Oncol. 2010; 28:

104. Rinehart J, Adjei AA, Lorusso PM, Waterhouse D, Hecht JR, Natale RB, et al. Multicenter phase II study of the oral MEK inhibitor, CI-1040, in patients with advanced non-small-cell lung, breast, colon, and pancreatic cancer. J Clin Oncol. 2004; 22:4456-62.

105. Corbalan-Garcia S, Yang SS, Degenhardt KR, Bar-Sagi D. Identification of the mitogen-activated protein kinase phosphorylation sites on human Sos1 that regulate interaction with Grb2. Mol Cell Biol. 1996; 16:5674-82.

106. Douville E, Downward J. EGF induced SOS phosphorylation in PC12 cells involves P90 RSK-2. Oncogene. 1997; $15: 373-83$.

107. Li X, Huang Y, Jiang J, Frank SJ. ERK-dependent threonine phosphorylation of EGF receptor modulates receptor downregulation and signaling. Cell Signal. 2008; 20:2145-55.

108. Hanafusa H, Torii S, Yasunaga T, Nishida E. Sprouty1 and Sprouty2 provide a control mechanism for the Ras/MAPK signalling pathway. Nat Cell Biol. 2002; 4:850-8.

109. Sun C, Hobor S, Bertotti A, Zecchin D, Huang S, Galimi F, et al. Intrinsic Resistance to MEK Inhibition in KRAS Mutant Lung and Colon Cancer through Transcriptional Induction of ERBB3. Cell Rep. 2014; 7:86-93.

110. Prahallad A, Sun C, Huang S, Di Nicolantonio F, Salazar R, Zecchin D, et al. Unresponsiveness of colon cancer to BRAF(V600E) inhibition through feedback activation of EGFR. Nature. 2012; 483:100-3.

111. Klinger B, Sieber A, Fritsche-Guenther R, Witzel F, Berry L, Schumacher D, et al. Network quantification of EGFR signaling unveils potential for targeted combination therapy. Mol Syst Biol. 2013; 9:673.

112. Dougherty MK, Müller J, Ritt DA, Zhou M, Zhou XZ, Copeland TD, et al. Regulation of Raf-1 by direct feedback phosphorylation. Mol Cell. 2005; 17:215-24.

113. Amit I, Citri A, Shay T, Lu Y, Katz M, Zhang F, et al. A module of negative feedback regulators defines growth factor signaling. Nat Genet. 2007; 39:503-12.

114. Fritsche-Guenther R, Witzel F, Sieber A, Herr R, Schmidt N, Braun S, et al. Strong negative feedback from 
Erk to Raf confers robustness to MAPK signalling. Mol Syst Biol. 2011; 7:489.

115. Wee S, Jagani Z, Xiang KX, Loo A, Dorsch M, Yao $\mathrm{Y}-\mathrm{M}$, et al. PI3K pathway activation mediates resistance to MEK inhibitors in KRAS mutant cancers. Cancer Res. 2009; 69:4286-93.

116. Lito P, Rosen N, Solit DB. Tumor adaptation and resistance to RAF inhibitors. Nat Med. 2013; 19:1401-9.

117. Corcoran RB, Ebi H, Turke AB, Coffee EM, Nishino M, Cogdill AP, et al. EGFR-mediated re-activation of MAPK signaling contributes to insensitivity of BRAF mutant colorectal cancers to RAF inhibition with vemurafenib. Cancer Discov. 2012; 2:227-35.

118. Yang H, Higgins B, Kolinsky K, Packman K, Bradley WD, Lee RJ, et al. Antitumor activity of BRAF inhibitor vemurafenib in preclinical models of BRAF-mutant colorectal cancer. Cancer Res. 2012; 72:779-89.

119. Capalbo C, Marchetti P, Coppa A, Calogero A, Anastasi E, Buffone A, et al. Vemurafenib and panitumumab combination tailored therapy in BRAF-mutated metastatic colorectal cancer: a case report. Cancer Biol Ther. 2014; 15:826-31.

120. Yaeger R, Cercek A, O'Reilly EM, Reidy DL, Kemeny N, Wolinsky $\mathrm{T}$, et al. Pilot Trial of Combined BRAF, and EGFR Inhibition in BRAF-Mutant Metastatic Colorectal Cancer Patients. Clin Cancer Res. 2015; 21:1313-20.

121. Corcoran RB, Atreya CE, Falchook GS, Infante JR, Hamid O, Messersmith WA, et al. Phase 1-2 trial of the BRAF inhibitor dabrafenib (D) plus MEK inhibitor trametinib (T) in BRAF V600 mutant colorectal cancer (CRC): Updated efficacy and biomarker analysis. J Clin Oncol. 32:5s, 2014.

122. Bendell JC, Atreya CE, André T, Tabernero J, Gordon MS, Bernards R, et al. Efficacy and tolerability in an open-label phase I/II study of MEK inhibitor trametinib (T), BRAF inhibitor dabrafenib (D), and anti-EGFR antibody panitumumab $(\mathrm{P})$ in combination in patients (pts) with BRAF V600E mutated colorectal cancer (CRC). J Clin Oncol. 32:5s, 2014.

123. Hong DS, Van Karlyle Morris, Fu S, Overman MJ, PihaPaul SA, Kee BK, et al. Phase 1B study of vemurafenib in combination with irinotecan and cetuximab in patients with BRAF-mutated advanced cancers and metastatic colorectal cancer. J Clin Oncol. 32:5s, 2014.

124. Tabernero J, Chan E, Baselga J, Blay J-Y, Chau I, Hyman DM, et al. VE-BASKET, a Simon 2-stage adaptive design, phase II, histology-independent study in nonmelanoma solid tumors harboring BRAF V600 mutations (V600m): Activity of vemurafenib (VEM) with or without cetuximab (CTX) in colorectal cancer (CRC). J Clin Oncol. 32:5s, 2014.
125. Ahronian LG, Sennott EM, Van Allen EM, Wagle N, Kwak EL, Faris JE, et al. Clinical Acquired Resistance to RAF Inhibitor Combinations in BRAF-Mutant Colorectal Cancer through MAPK Pathway Alterations. Cancer Discov. 2015; 5:358-67.

126. Poulikakos PI, Zhang C, Bollag G, Shokat KM, Rosen N. RAF inhibitors transactivate RAF dimers and ERK signalling in cells with wild-type BRAF. Nature. 2010; 464:427-30.

127. Heidorn SJ, Milagre C, Whittaker S, Nourry A, NiculescuDuvas I, Dhomen N, et al. Kinase-dead BRAF, and oncogenic RAS cooperate to drive tumor progression through CRAF. Cell. 2010; 140:209-21.

128. Hatzivassiliou G, Song $\mathrm{K}$, Yen I, Brandhuber BJ, Anderson DJ, Alvarado R, et al. RAF inhibitors prime wild-type RAF to activate the MAPK pathway and enhance growth. Nature. 2010; 464:431-5.

129. Cox AD, Der CJ. The RAF Inhibitor Paradox Revisited. Cancer Cell. 2012; 21:147-9.

130. Hatzivassiliou G, Haling JR, Chen H, Song K, Price S, Heald R, et al. Mechanism of MEK inhibition determines efficacy in mutant KRAS- versus BRAF-driven cancers. Nature. 2013; 501:232-6.

131. Condelli V, Piscazzi A, Sisinni L, Matassa DS, Maddalena F, Lettini G, et al. TRAP1 is involved in BRAF regulation and downstream attenuation of ERK phosphorylation and cell-cycle progression: a novel target for BRAF-mutated colorectal tumors. Cancer Res. 2014; 74:6693-704.

132. Parsons DW, Wang T-L, Samuels Y, Bardelli A, Cummins JM, DeLong L, et al. Colorectal cancer: mutations in a signalling pathway. Nature. 2005; 436:792.

133. She Q-B, Halilovic E, Ye Q, Zhen W, Shirasawa S, Sasazuki T, et al. 4E-BP1 is a key effector of the oncogenic activation of the AKT and ERK signaling pathways that integrates their function in tumors. Cancer Cell. 2010; 18:39-51.

134. Boussemart L, Malka-Mahieu H, Girault I, Allard D, Hemmingsson O, Tomasic G, et al. eIF4F is a nexus of resistance to anti-BRAF and anti-MEK cancer therapies. Nature. 2014; 513:105-9.

135. Van Geel R, Elez E, Bendell JC, Faris JE, Lolkema MPJK, Eskens F, et al. Phase I study of the selective BRAFV600 inhibitor encorafenib (LGX818) combined with cetuximab and with or without the $\alpha$-specific PI3K inhibitor BYL719 in patients with advanced BRAF-mutant colorectal cancer. J Clin Oncol. 32:5s, 2014. 32(5s, 2014).

136. Coffee EM, Faber AC, Roper J, Sinnamon MJ, Goel G, Keung L, et al. Concomitant BRAF, and PI3K/ mTOR blockade is required for effective treatment of BRAF(V600E) colorectal cancer. Clin Cancer Res. 2013; 19:2688-98. 
137. Faller WJ, Jackson TJ, Knight JRP, Ridgway RA, Jamieson T, Karim SA, et al. mTORC1-mediated translational elongation limits intestinal tumour initiation and growth. Nature. 2015; 517:497-500.

138. Liu J, Pan S, Hsieh MH, Ng N, Sun F, Wang T, et al: Targeting Wnt-driven cancer through the inhibition of Porcupine by LGK974Proc Natl Acad Sci USA. 2013;110: 20224-9.

139. Lin L, Sabnis AJ, Chan E, Olivas V, Cade L, Pazarentzos E, et al. The Hippo effector YAP promotes resistance to RAF- and MEK-targeted cancer therapies. Nat Genet. 2015; 47:250-6.

140. Keren-Paz A, Emmanuel R, Samuels Y. YAP and the drug resistance highway. Nat Genet. 2015; 47:193-4.

141. Schulze A, Lehmann K, Jefferies HB, McMahon M, Downward J. Analysis of the transcriptional program induced by Raf in epithelial cells. Genes Dev. 2001; 15:981-94.

142. Kreeger PK, Mandhana R, Alford SK, Haigis KM, Lauffenburger DA. RAS mutations affect tumor necrosis factor-induced apoptosis in colon carcinoma cells via ERK-modulatory negative and positive feedback circuits along with non-ERK pathway effects. Cancer Res. 2009; 69:8191-9.

143. Straussman R, Morikawa T, Shee K, Barzily-Rokni M, Qian ZR, Du J, et al. Tumour micro-environment elicits innate resistance to RAF inhibitors through HGF secretion. Nature. 2012; 487:500-4.

144. Calon A, Lonardo E, Berenguer-Llergo A, Espinet E, Hernando-Momblona X, Iglesias M, et al. Stromal gene expression defines poor-prognosis subtypes in colorectal cancer. Nat Genet. 2015; 47:320-9.

145. Polyak K, Marusyk A. Cancer: Clonal cooperation. Nature. 2014; 508:52-3.

146. Hu-Lieskovan S, Mok S, Homet Moreno B, Tsoi J, Robert L, Goedert L, et al. Improved antitumor activity of immunotherapy with BRAF and MEK inhibitors in BRAF(V600E) melanoma. Sci Transl Med. 2015; 7:29ra41

147. Sers C, Kuner R, Falk CS, Lund P, Sueltmann H, Braun M, et al. Down-regulation of HLA Class, I, and NKG2D ligands through a concerted action of MAPK and DNA methyltransferases in colorectal cancer cells. Int $\mathrm{J}$ Cancer. 2009; 125:1626-39.

148. Koelzer VH, Dawson H, Andersson E, Karamitopoulou E, Masucci GV, Luigi A et al. Active immunosurveillance in the tumor microenvironment of colorectal cancer is associated with low frequency tumor budding and improved outcome. Transl Res. 2015; pii:S1931-5244(15)00083-3. 